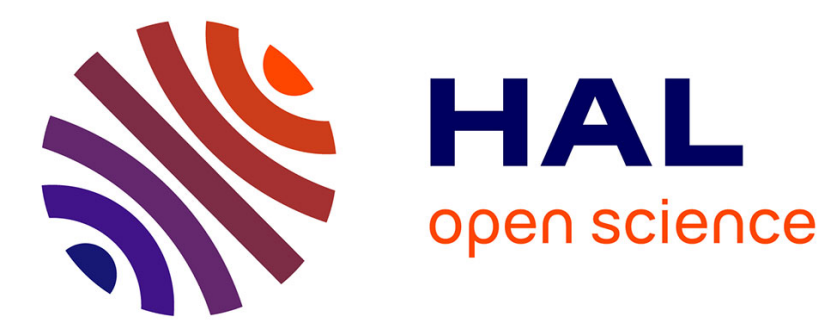

\title{
Investigations on the critical speed suppressing by using electromagnetic actuators
}

Jarir Mahfoud, Johan Der Hagopian

\section{To cite this version:}

Jarir Mahfoud, Johan Der Hagopian. Investigations on the critical speed suppressing by using electromagnetic actuators. Smart Structures and Systems, 2012, 9 (4), pp.303-311. hal-00824272

\section{HAL Id: hal-00824272 \\ https://hal.science/hal-00824272}

Submitted on 21 May 2013

HAL is a multi-disciplinary open access archive for the deposit and dissemination of scientific research documents, whether they are published or not. The documents may come from teaching and research institutions in France or abroad, or from public or private research centers.
L'archive ouverte pluridisciplinaire HAL, est destinée au dépôt et à la diffusion de documents scientifiques de niveau recherche, publiés ou non, émanant des établissements d'enseignement et de recherche français ou étrangers, des laboratoires publics ou privés. 


\title{
Investigations on the critical speed suppressing by using electromagnetic actuators
}

\author{
Jarir Mahfoud $^{1 \star}$ and Johan Der Hagopian ${ }^{1}$ \\ Université de Lyon - Laboratoire de Mécanique des Contacts et des Structures - UMR CNRS 5259, \\ Institut National des Sciences Appliquées de Lyon, FRANCE.
}

\begin{abstract}
The possibility of suppressing critical speeds by using electromagnetic actuators (EMAs) is assessed experimentally in this paper. The system studied is composed of a horizontal flexible shaft supported by two ball bearings at one end and one roller bearing that is located in a squirrel cage at the other end. Four identical EMAs supplied with constant current are utilized. The EMAs associated to the squirrel cage constitutes the hybrid bearing. Results obtained, show that the constant current, when applied to the EMAs, produces a shift of the first critical speed toward lower values. Moreover, the application of constant current for a speed interval around the critical speed enables a smooth run-up or run-down without crossing any resonance.
\end{abstract}

\section{Keywords:}

Critical speeds, Electromagnetic actuators, Rotordynamics, Hybrid bearings, Experiments.

"Corresponding author. Associate Professor, E-mail: Jarir.mahfoud@insa-lyon.fr 


\section{Introduction}

Modern rotating machinery becomes lighter and operates with higher speed due to the enhancement of its performance and efficiency. Consequently, the number of critical speeds included in the operating frequency range increases, and the rotor is more sensitive to external excitations. In addition, the rotor requires more stable operating conditions and the attenuation of the generated vibrations. These vibrations are responsible for the performance degradations and also the excessive acoustic noises and fatigue-related damages.

Due to the rapid development in actuator technology, electronics, sensors, signal processing and machine design, the smart machine technology is an actual research topic for mechatronic and engineering (Larsonneur 2008, Maslen 2008).

Rotating machines mounted on Active Magnetic Bearings (AMB) are representative of tendency of developing smart machine and have been successfully applied in industrial turbomachinery (Schweitzer 2003). Their main advantages are contact-less working environments, no sealing constraints, frictionless suspension, and their capacity to operate in active systems. They are well-suited for contactless operation as actuators and sensors in rotating machinery (Kulesza 2010, Lei 2008, Kasarda 2007, Mani 2006, Aenis 2002, Kasarda 2004). AMB devices in conjunction with conventional support bearings are utilized either as active magnetic dampers (Souza 2010), or for controlling the instability (El-Shafei 2007, Souza 2009). In this case, the AMB is considered as an ElectroMagnetic Actuator (EMA).

The work presented in this paper is part of a research program aimed at controlling the dynamic behavior of rotating machinery when the latter crosses critical speeds and instability zones. In a previous work (Der Hagopian 2010), the influence of EMAs on the frequency response of a harmonically excited cantilever beam is investigated numerically and experimentally. The EMAs was powered with different constant electrical currents, and the effect of the current variation on the dynamic behavior of the system was analyzed. 
Results indicated that EMAs produce a softening behavior in the system, the resonance curve shifts toward smaller values. The aim in this paper is to analyze the dynamic behavior of a rotating machine in the presence of EMAs supplied with constant current. The softening effects of EMA is well known, the objective here is to use these effects to make it simpler to cross a critical speed. The developed approach is not an alternative for the active control, which is necessary to attenuate the effects of the external excitations.

The paper is organized as follow: the test rig is first described then; the designed EMAs are presented and identified experimentally and finally the results stemming from experimentations are discussed.

\section{Experimental test rig}

The system studied (Fig. 1) is a test machine composed of a horizontal flexible shaft of $0.04 \mathrm{~m}$ diameter containing two rigid discs. The rotor is driven by an electrical motor that can accelerate the shaft until the rotation of $10,000 \mathrm{rev} / \mathrm{min}$ including 2 first critical speeds. In this study, only the first critical speed is considered. The shaft is supported by bearings located at its ends, as follows: a roller bearing (B2) near the drive end and two ball bearings at the other end (B1). The roller bearing is located in a squirrel cage attached to the framework of the test rig by three identical flexible steel beams; this arrangement leads to a slight dissymmetric dynamic behavior of the test rig. The Electro-Magnetic Actuators (EMAs) located on the external cage constitutes a smart active bearing and provides nonlinearity in the dynamics of the system.

The displacements are measured by using four proximity sensors (Vibrometer TQ 103) arranged perpendicularly in two measurement planes located along the y axis (Fig. 1), namely, measurement plane \#1 and measurement plane \#2, the latter is located close to the hybrid bearing. The sensors are labeled $\mathrm{C} 1$ and $\mathrm{C} 4$ for the horizontal direction and $\mathrm{C} 2$ and C3 for the vertical direction. 
The data acquisition device used to collect experimental data was the SCADAIII interface of LMS $\AA$ that enables real time data acquisition. Several codes of LMS $\AA$ modal analysis software were used for data processing. The sampling frequency was set to 4096 $\mathrm{Hz}$.

\section{Actuators design and identification}

EMAs are designed to deliver a maximum attraction force of $300 \mathrm{~N}$, and the maximum possible current is $5.0 \mathrm{~A}$. The control input could be either a current or a voltage. For practical reasons, aiming at simplifying the electrical EMA model, a current control configuration was utilized.

Since an EMA can only produce attractive forces, Four "identical" EMA supplied by constant currents are utilized. Each EMA is composed of a ferromagnetic circuit and an electrical circuit. The ferromagnetic circuit has two parts: an $(E)$ shape, which receives the induction coil, and an $(I$ ) shape, which is fixed to the squirrel cage. Both parts are made of sets of insulated ferromagnetic sheets. The quality of the ferromagnetic circuit alloy is considered high enough and the nominal air gap between the stator and the beam is small enough to consider magnetic loss as negligible. The geometries of the actuators are summarized in Fig. 2.

Assuming negligible eddy current effects and conservative flux, the relationship between the electromagnetic force $\left(\mathrm{F}_{\mathrm{em}}\right)$, air gap $(e)$, gap distance $\left(\delta_{a}\right)$ and current $(I)$ for an action axe can be expressed as:

$$
F_{e m}=\frac{N^{2} \mu_{0} a f I^{2}}{2\left(\left(e+\delta_{a}\right)+\frac{b+c+d-2 a}{\mu_{r}}\right)^{2}}-\frac{N^{2} \mu_{0} a f I^{2}}{2\left(\left(e-\delta_{a}\right)+\frac{b+c+d-2 a}{\mu_{r}}\right)^{2}}
$$

where $(a, b, c, d$ and $f)$ correspond to the geometrical characteristics of the actuator and $\mu_{0}$ is the magnetic permeability of a vacuum $\left(4 \pi \times 10^{-7} \mathrm{H} / \mathrm{m}\right) . \mu_{r}$ is the relative magnetic permeability (dimensionless) that is a function of the air gap and can be varied according to 
temperature. Its value is based on manufacturer's specifications and is generally not known with great accuracy and has to be identified.

The presence of these electromagnetic forces introduce a softening effects on the dynamics of the system and produce a shift of the first resonance frequency towards lower values. Mahfoud et al. (2011) show that this shift depends on the constant current value applied for a given air gap value.

A model of the actuator is necessary in order to adjust and to control the actual air gaps. In this model, the inputs are the current and the gap distance; the output is the force. The geometrical parameters could be measured precisely; the only unknown is the relative permeability that has to be determined experimentally. The relative permeability is determined as:

$$
\mu_{r}=\frac{\beta(b+c+d-2 a)}{1-\beta e} \quad ; \quad \beta=\sqrt{\frac{2 F_{e m}}{N^{2} \mu_{0} a f I^{2}}}
$$

A specific experimental arrangement was realized (Fig. 3) in order to measure the force generated by one actuator, for several air gaps and for increasing and decreasing values of the input current. We supposed that the three other actuators have the same characteristics.

The generated forces due to increasing and decreasing input currents are measured for several air gaps (Fig. 4).

The results obtained show that the hysteresis effect (due to electromagnetic flux) appears to be negligible and the generated forces are proportional to the current square value. In the model presented here, the relative permeability is assumed to be constant for low flux density. The mean value determined for the model is 950 .

The measured forces due to an increasing current sweep are compared with those generated by the model for different air gaps in Fig. 5. Same trends were observed for a decreasing sweep. The model identified, describes closely the behavior of the EMAs 
especially for large air gaps. From the results obtained, the operating conditions are chosen as $0.6 \mathrm{~mm}$ for the air gap (theoretical value) and $4 \mathrm{~A}$ for the current.

\section{Experimental investigations}

Experiments are carried out in order to assess the dynamic behavior with and without constant current. Actuators are mounted with the same air gap of $0.6 \mathrm{~mm}$. The measurements show that the air gaps realized are: $0.621 \mathrm{~mm}$ for actuator $\# 1,0.666 \mathrm{~mm}$ for \#2, $0.641 \mathrm{~mm}$ for \#3 and $0.715 \mathrm{~mm}$ for actuator \#4. Two configurations are considered in this paper: without current $(0 \mathrm{~A})$ and with constant current $(4 \mathrm{~A})$. Even if the air gaps were different, the actuators have been supplied with the same current. The dynamic behavior of the test rig is assessed first at rest, and then during run-up or run-down.

\subsection{Behavior at rest}

This step is important in order to quantify the shift value of the first critical speed, and to verify the stability of the behavior with the chosen operating conditions. A GWV20B of 110 $\mathrm{N}$ electro-dynamic shaker provided by SS100 power amplifier of Gearing \& Watson LTD is utilized (Fig.6).

An increasing and decreasing, sinusoidal sweep from 22 to $55 \mathrm{~Hz}$ is performed for the two configurations (with and without current). The sweep rate is chosen such that the measurements correspond to the steady state permanent conditions. The frequency range chosen includes the first resonance of the test rig. It is worth mentioning that for the configuration without current, no difference is observed between the two sweeps. Thus, this configuration is presented by only one curve. The excitation is introduced on disc D2 for both directions, horizontal and vertical. The applied forces are measured by using a piezoelectric force sensor (B\&K 8200).

The transfer functions measured in the vertical direction at measurement plane \#2 are presented in Fig. 7. The dissymmetric behavior could be noticed easily on the system "linear" response (without current). Two frequencies, 44.4 and $45.6 \mathrm{~Hz}$ are observed; they 
correspond to the backward and forward whirl (2,644 and 2,736 rev/min). The application of the current produces, as expected, a softening effects. It was difficult to identify the two frequencies, only the backward frequency can be easily observed at $38.4 \mathrm{~Hz}$. Also, the hysteresis effects seem to be negligible.

The frequency shift is significant $(13 \%)$. The frequency ranges for the two configurations is well separated, which can facilitate the resonance suppressing. These conclusions have to be confirmed during the rotating testing.

\subsection{Behavior during run-up and run-down}

The amplitude of the displacements during a run-up from 800 to $4000 \mathrm{rev} / \mathrm{min}$ in 30 seconds with linear speed variation was measured; the displacements stemming from sensor C1 are presented in Fig. 8. This acceleration rate is the highest that could be used for this test rig. Here also, it could be noticed that the constant current produces a shift of the first critical speeds toward lower values. For the linear system, two resonances are observed for 2,540 and 2,590 rev/min. While, when applying the constant current, these frequencies are shifted to 2,240 and $2,300 \mathrm{rev} / \mathrm{min}$. The same trends were observed for the run-down and for the other sensors.

As seen in the static testing, the frequency shift is significant and the frequency ranges for the two configurations is well separated. The second step consists on the application of the current only in the vicinity of the critical speed. The four actuators are supplied with the same constant currents (4 A) when reaching the speed of 2,400 rev/min (higher than the critical speeds of the "non-linear" system and lower than the "linear" system critical speeds); then the currents are switched off for a speed higher than the linear system critical speed (higher than 2,736 rev/min). For the testing presented in this study, the current was switched off at 2,800 rev/min. 
The displacements stemming from sensor C2 during the run-up from 800 to 4000 $\mathrm{rev} / \mathrm{min}$ in 90 seconds with linear speed variation are presented in Fig. 9. This acceleration rate is the usual rate utilized for the test rig.

It could be noticed that the rotor does not cross the critical speed during the run-up. The same behavior was also noticed during the run-down (Fig. 10).

The electromagnetic actuators, utilized in this configuration, provide a "smooth" runup or run-down and could enable the suppression of critical speeds. It is worth mentioning that only the first critical speed was monitored in this study. The position of the hybrid bearing corresponds to a vibration node for the second mode; consequently the electromagnetic actuators have no effects on the dynamic behavior.

\section{Conclusions}

The possibility of suppressing critical speeds by using electromagnetic actuators is assessed in this study. The approach consists on introducing "when needed" a softening behavior during operation so that the rotating machine does not cross any critical speeds during run-up or run-down.

The constant current, when applied to the EMAs, produces a shift of the first critical speed toward lower values. The phenomena of amplitude jump and the hysteresis effects produced during run-up or run-down are negligible. The application of a constant current for a speed interval around the critical speed enables a smooth run-up or run-down without crossing any resonance.

In this study, only the first critical speed was monitored. The position of the hybrid bearing corresponds to a vibration node for the second mode; consequently the electromagnetic actuators have no effects on the dynamic behavior. This approach requires a good knowledge of the dynamic behavior of the studied system in order to apply the current for the suitable speed range. It was noticed that the produced dynamic behavior depends on (and is sensitive to) the current intensity and the air gap value. 
The amplitude response increases when applying the current (step input), on the other hand introducing the current with a given rate may introduce instability. Researches are going on in order to optimize the dynamic behavior as a function of the current intensity and the air gap values.

This study is an additional interesting utilization of EMA and is not an alternative for the active control, which is necessary to attenuate the effects of the external excitations.

\section{References}

Aenis, M., Knopf, E. and Nordmann, R. (2002), "Active magnetic bearings for the identification and fault diagnosis in turbomachinery", Mechatronics, 12, 1011-1021.

Der Hagopian, J., Belhaq, M., Seibold, Z. et Mahfoud, J. (2010), "Maîtrise de Phénomènes de Saut dans les Réponses Fréquentielles des Structures avec Non Linéarité Localisée", Machines et Industries, 11 (5), 419-425.

El-Shafei, A. and Dimitri, A.S. (2010), "Controlling journal bearing instability using active magnetic bearings", Journal of Engineering for Gas Turbines and Power, 132, 1-9.

Kasarda, M., Marshall, J. and Prins, R. (2007), "Active magnetic bearing based force measurement using the multi-point technique", Mechanics Research Communications, 34, pp. $44-53$

Kasarda, M., Mendoza, H., Kirk, R.G. and Wicks, A. (2004), "Reduction of subsynchronous vibrations in a single-disk rotor using an active magnetic damper", Mechanics Research Communications, 31, 689-695.

Kulesza, Z., Sawicki, J.T. and Storozhev, D.L. (2010), "Smart Properties of AMB Supported Machines for Rotor Crack Detection: Experimental and Analytical Study", Proceedings of the 8th IFToMM International Conference on Rotordynamics, September 12-15, KIST, Seoul, Korea. 
Larsonneur, R. and Richard, P. (2008), "Smart Turbomachines using Active Magnetic Bearings", Paper GT2008-51299, ASME Turbo Expo, Berlin, Germany, June 9-13.

Lei, S. and Palazzolo, A. (2008), "Control of flexible rotor systems with active magnetic bearings", Journal of Sound and Vibration, 314 (1-2), 19-38.

Mahfoud, J. and Der Hagopian, J. (2011), "Fuzzy Active Control Of Flexible Structures By Using Electromagnetic Actuators", ASCE's Journal of Aerospace Engineering, 24 (3), 329337.

Mani, G., Quinn, D.D. and Kasaeda, M. (2006), "Active health monitoring in a rotating cracked shaft using active magnetic bearings as force actuators", Journal of Sound and Vibration, 294, 454-465.

Maslen, E. H. (2008), "Smart Machine Advances in Rotating Machinery". IMechE, Exeter, UK, 8-10 September.

Schweitzer, G., Bleuler, H. and Traxler, A. (2003), Active Magnetic Bearings - Basics, Properties and Applications, vdf Hochschulverlag AG, ETH, Zurich.

Souza Morais, T., Steffen Jr, V., Mahfoud, J. and Der Hagopian, J. (2010), "Unbalance Identification in Nonlinear Rotors", Proceedings of the 8th IFToMM International Conference on Rotordynamics, September 12-15, KIST, Seoul, Korea.

Souza Morais, T., Steffen Jr, V., Mahfoud, J. and Der Hagopian, J. (2009), "Monitoring Cracked Shaft By Using Active Electro-Magnetic Actuator - Numerical Simulation", 20th International Congress of Mechanical Engineering, COBEM 2009, November 15-20, Gramado, RS, Brazil. 


\section{Figure caption}

Figure $1 \quad$ Experimental test rig

Figure 2 EMA details

Figure 3 Experimental arrangement for the actuator identification

Figure $4 \quad$ Measured forces and relative permeability versus current for several air gaps

Figure $5 \quad$ Measured and calculated forces versus current for several air gaps

Figure $6 \quad$ Experimental arrangement for static testing

Figure $7 \quad$ Transfer function, C3, sinusoidal sweep, with and without current

Figure 8 Displacement amplitude, C2, 800 to $4000 \mathrm{rev} / \mathrm{min}$ in $30 \mathrm{sec}$

Figure 9 Displacement amplitude, C2, run-up

Figure 10 Displacement amplitude, C2, run-down 


\section{FIGURES}

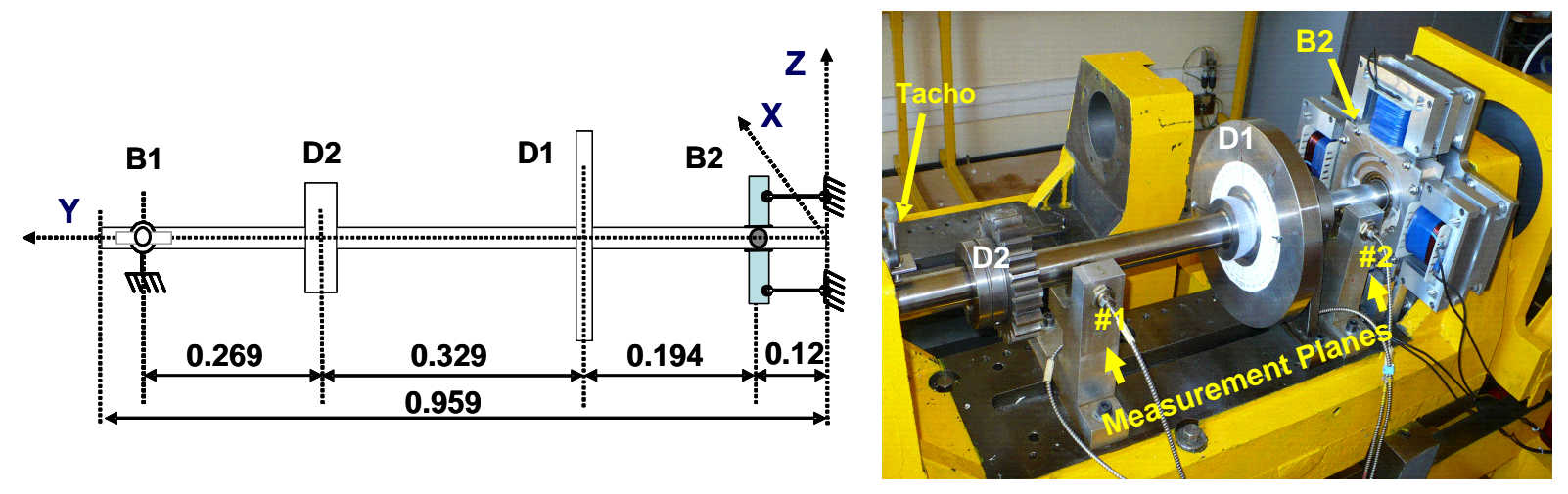

Figure 1. Experimental test rig 


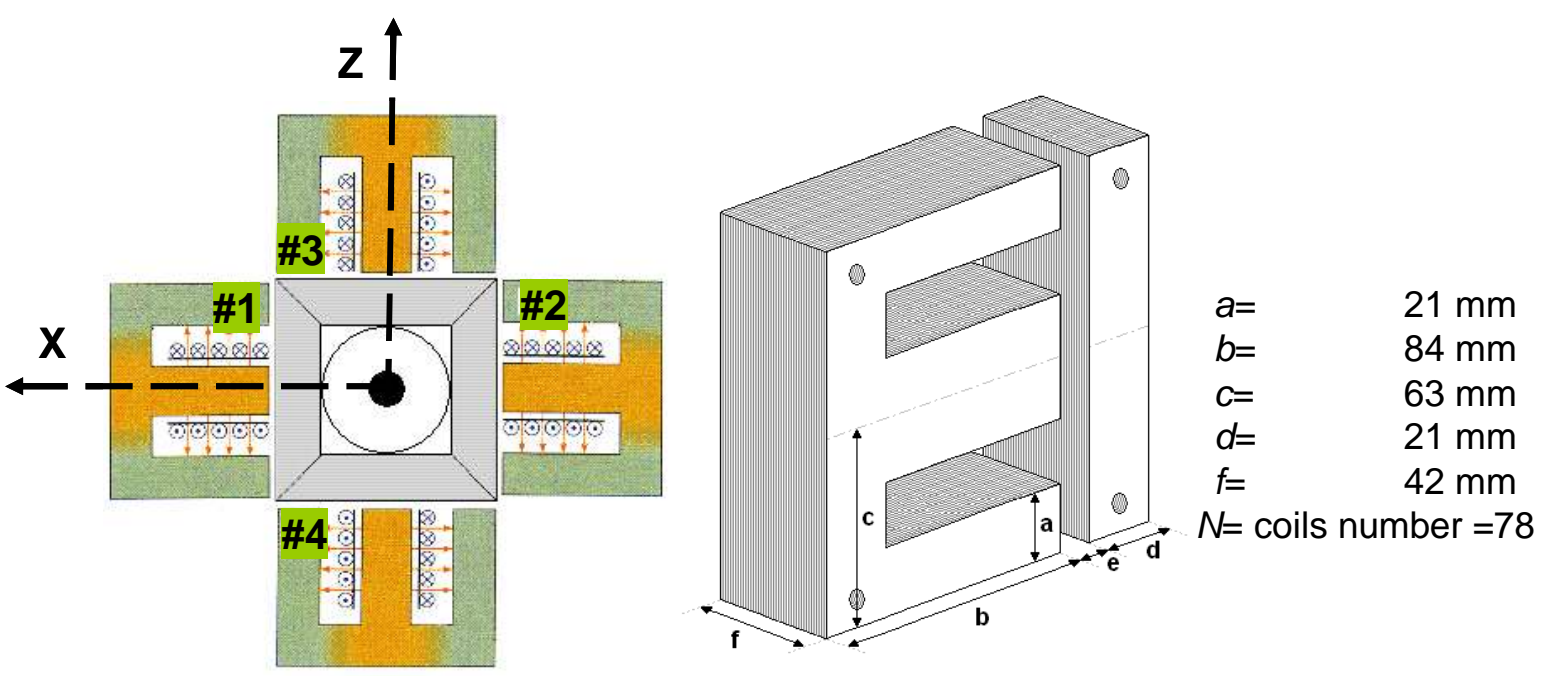

Figure 2. EMA details 


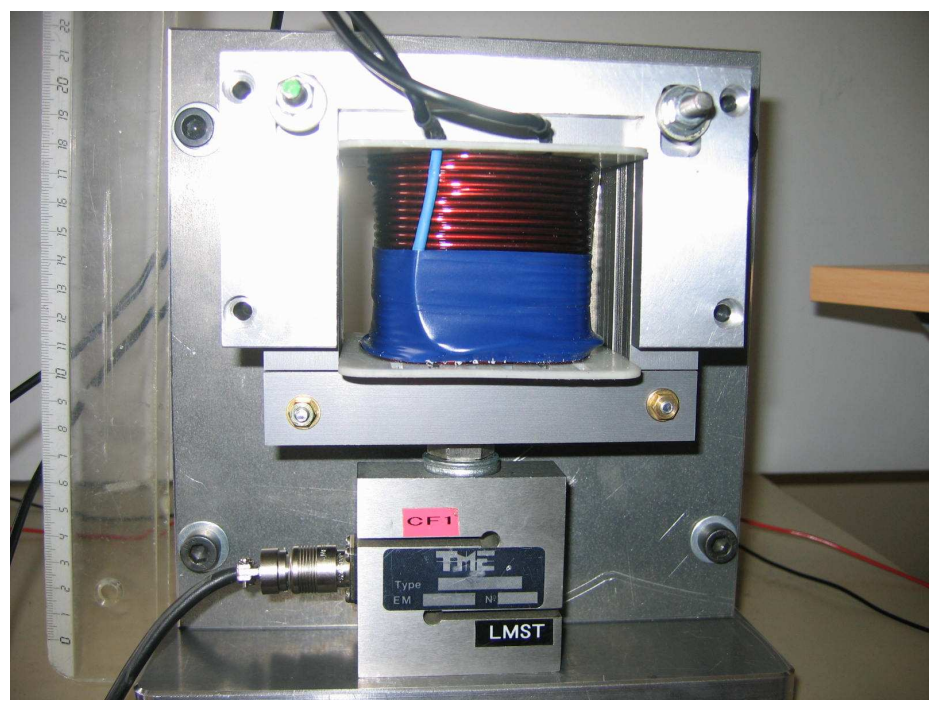

Figure 3. Experimental arrangement for the actuator identification 


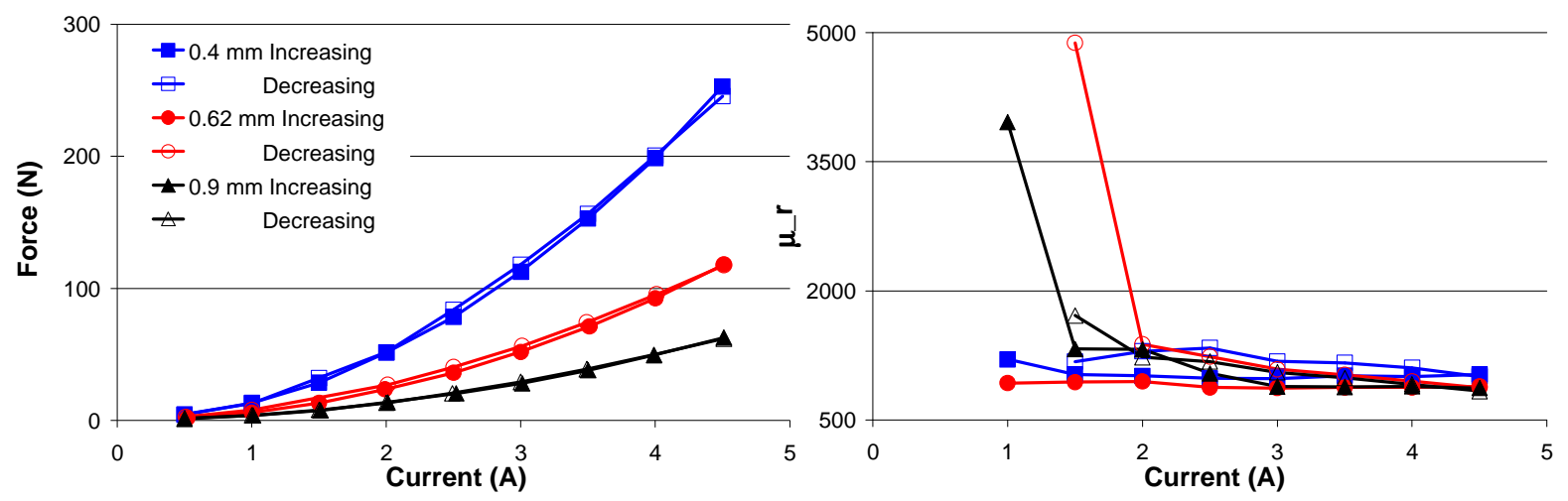

Figure 4. Measured forces and relative permeability versus current for several air gaps 


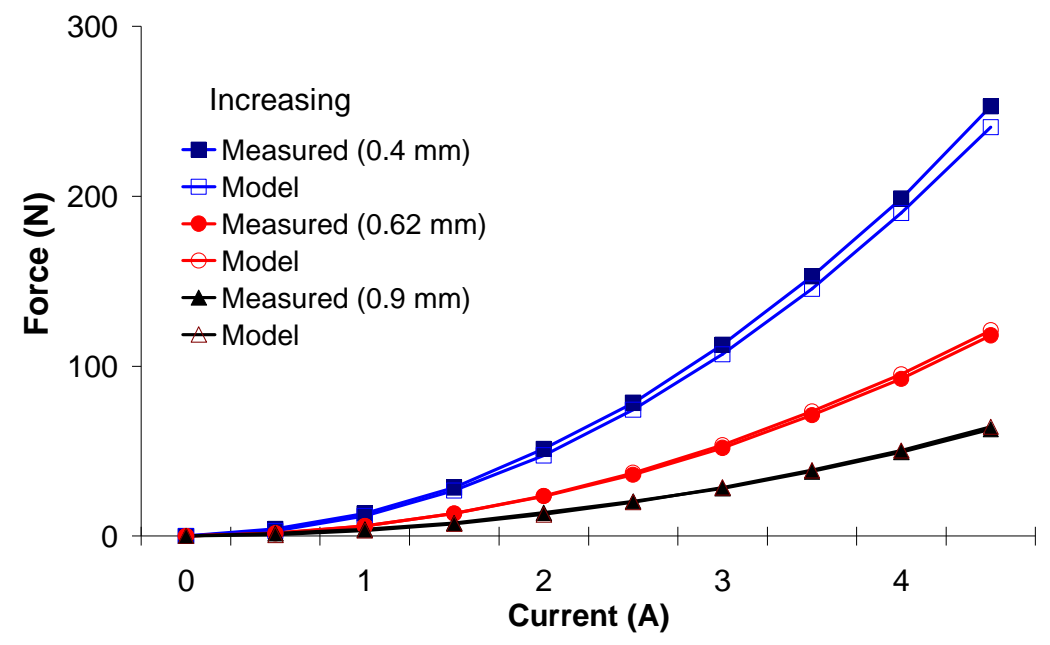

Figure 5. Measured and calculated forces versus current for several air gaps 


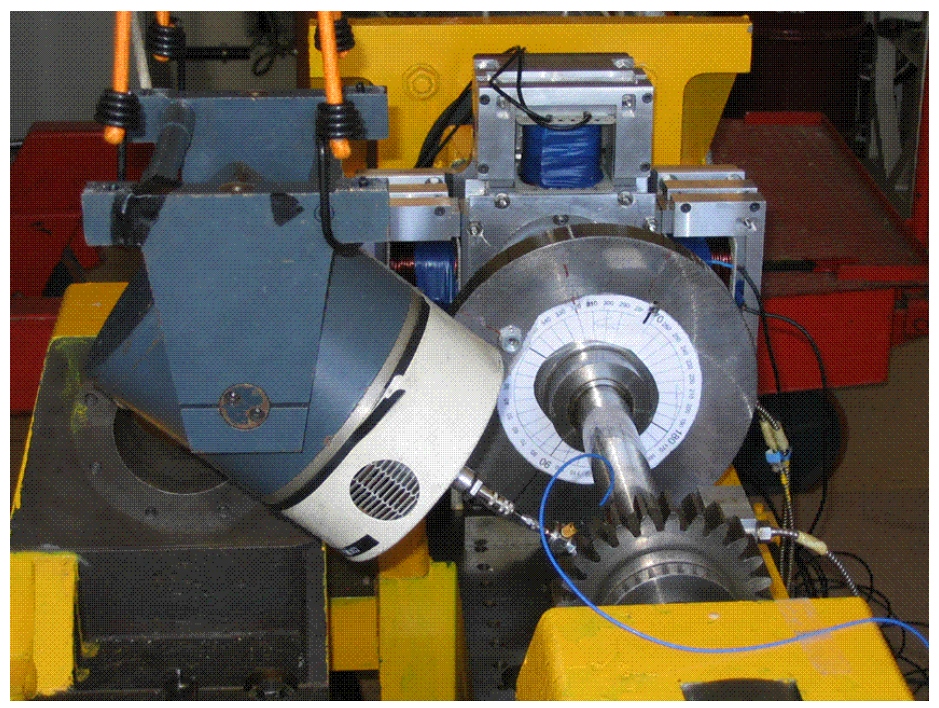

Figure 6. Experimental arrangement for static testing 


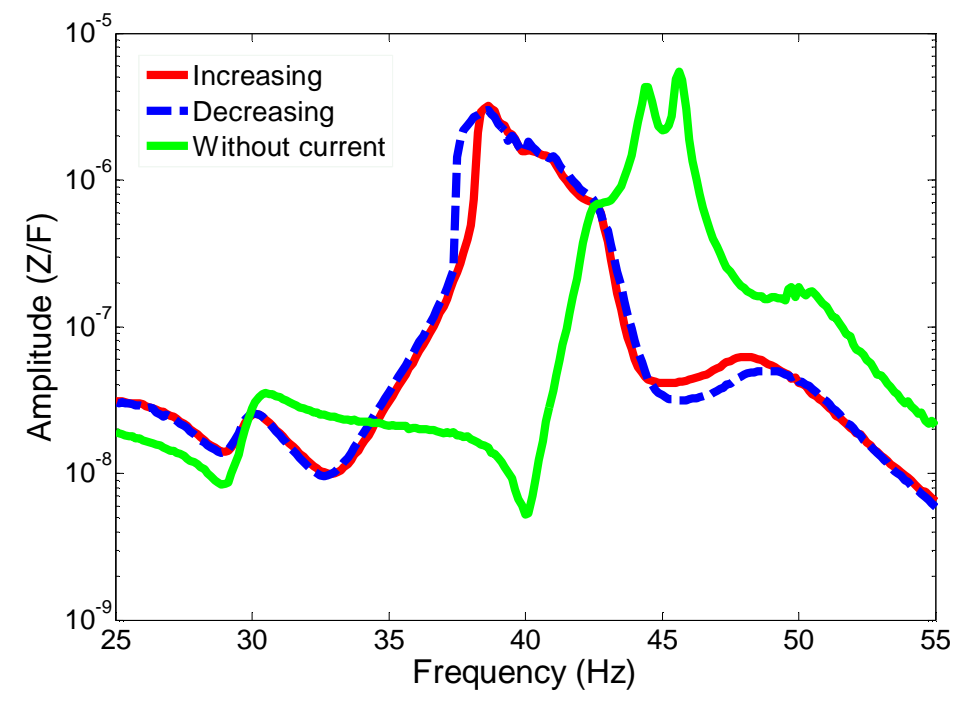

Figure 7. Transfer function, C3, sinusoidal sweep, with and without current 

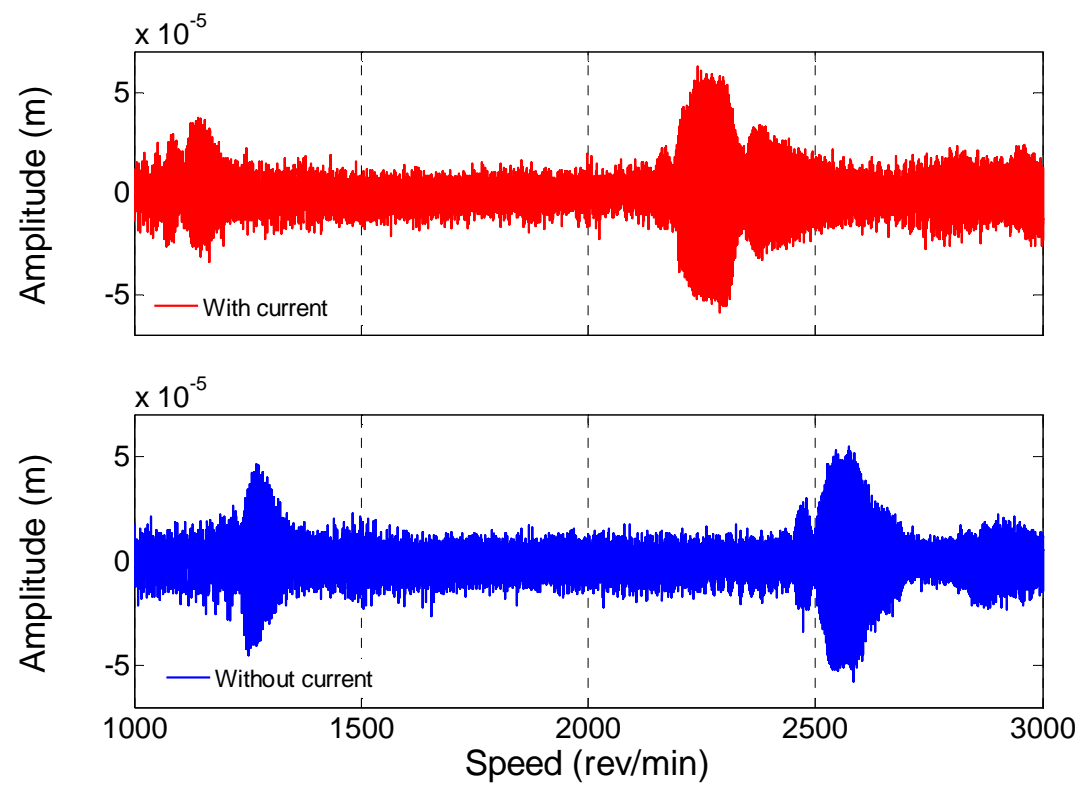

Figure 8. Displacement amplitude, C2, 800 to $4000 \mathrm{rev} / \mathrm{min}$ in $30 \mathrm{sec}$ 


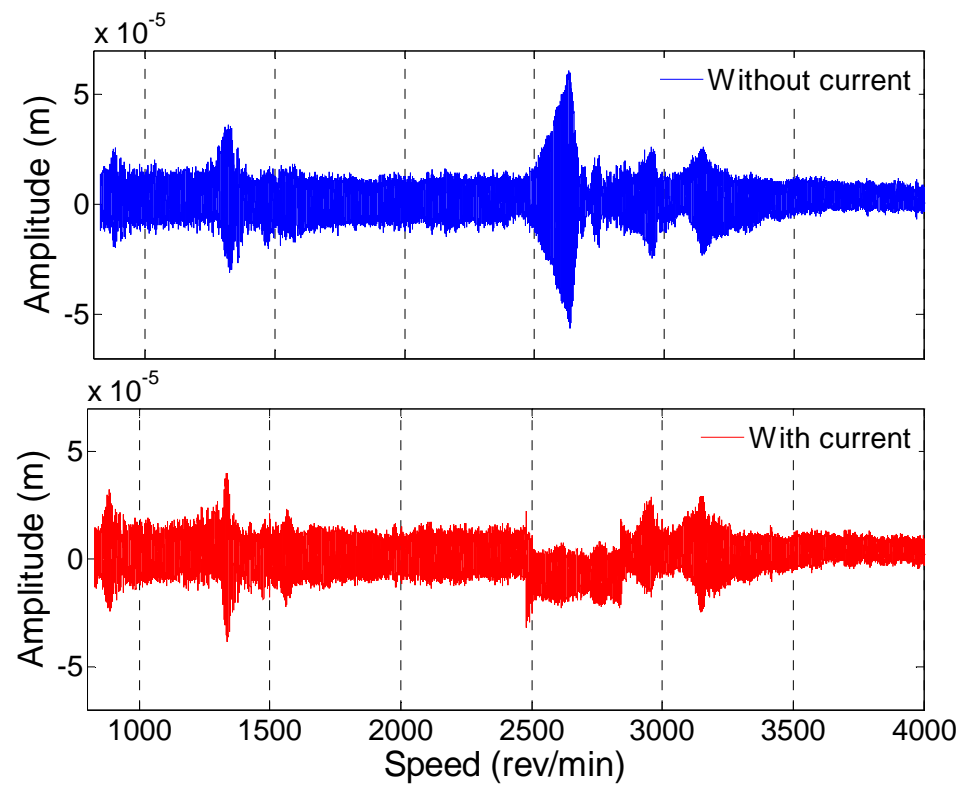

Figure 9. Displacement amplitude, C2, run-up. 


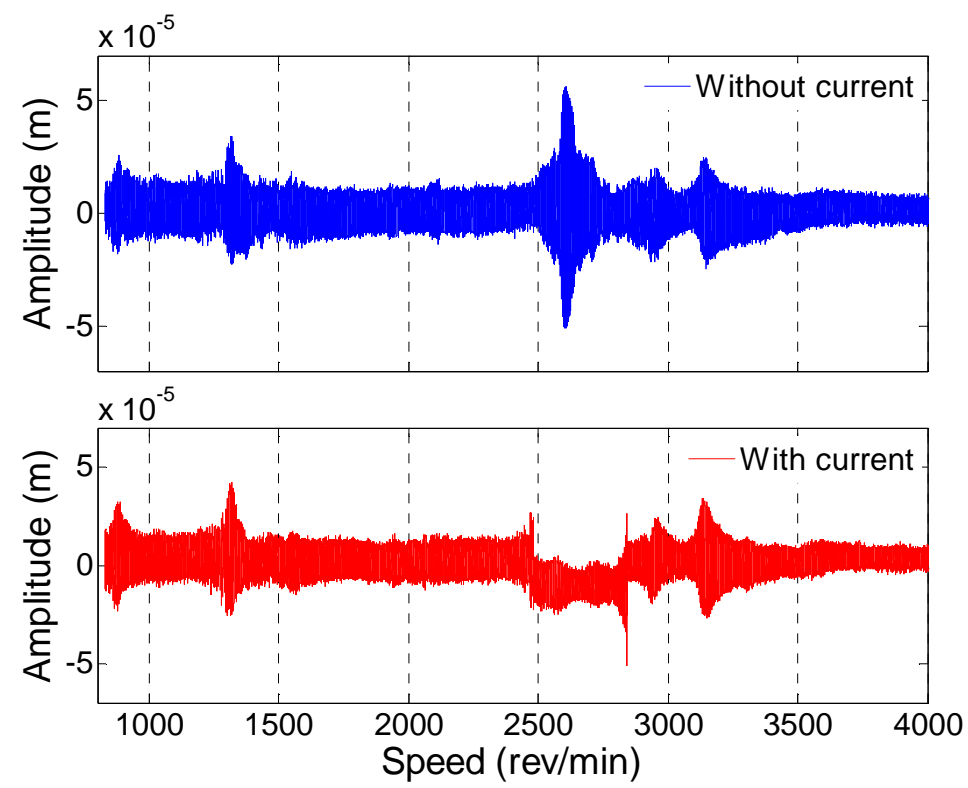

Figure 10. Displacement amplitude, C2, run-down. 